\title{
IMPLEMENTASI METODE VLSM (VARIABLE LENGTH SUBNET MASK) PADA PEMETAAN IP ADDRESS LAN (LOCAL AREA NETWORK) STIPER SRIWIGAMA PALEMBANG
}

\author{
Rahmat Novrianda D \\ Program Studi Teknik Komputer, Fakultas Vokasi, Universitas Bina Darma, \\ Jalan Jenderal A. Yani No. 3, Palembang, Indonesia \\ E-mail:rahmat.novrianda.d@gmail.com
}

\begin{abstract}
Abstrak
Pemetaan IP (Internet Protocol) Address pada setiap user yang ada di LAN (Local Area Network) STIPER Sriwigama Palembang saat ini masih dilakukan secara manual dan terkadang tanpa mencatat IP address yang telah diberikan pada user-user sebelumnya sehingga terjadi kesamaan IP address yang menyebabkan bentrokan saat pengiriman data. Hal inilah yang menjadi penyebab dasar sehingga peneliti bermaksud mengimplementasikan metode VLSM (Variable Length Subnet Mask) sehingga dapat memetakan IP address untuk user ke dalam beberapa bagian. Pada STIPER Sriwigama Palembang dibagi beberapa bagian user yaitu: Ketua, Wakil Ketua, LPPM, Administrasi, Dosen, Staff, Perpustakaan dan Mahasiswa. Perhitungan pemetaan IP address dengan metode VLSM ini diawali dari jumlah user yang terbanyak dari beberapa bagian yang telah dibagi di atas. Pemetaan IP ini menjadi solusi dari permasalahan yang terjadi pada STIPER Sriwigama Palembang sehingga dengan metode VLSM tidak lagi terjadi bentrokan IP address karena setiap user telah memperoleh IP address dan subnet mask yang berbeda-beda.
\end{abstract}

Kata kunci-Pemetaan, IP address, VLSM, subnet mask

\begin{abstract}
IP (Internet Protocol) address mapping to every user in the LAN (Local Area Network) STIPER Sriwigama Palembang is still done manually and sometimes without note the IP address that has been given to previous users so even the same IP address that causes clash when sending data. This is the basic cause so that the researcher intends to implement VLSM (Variable Length Subnet Mask) method so that it can mapping IP address for user into some parts. In STIPER Sriwigama Palembang divided into several parts of the user are Chairman, Vice Chairman, LPPM, Administration, Lecturer, Staff, Library and Student. Calculation of IP address mapping with VLSM method is started from the largest number of users from several parts that have been divided above. IP mapping is a solution of the problems that occur in STIPER Sriwigama Palembang so that with VLSM method no longer occur IP address clashes because each user has obtained different IP address and subnet mask.
\end{abstract}

Keywords-Mapping, IP address, VLSM, subnet mask 


\section{PENDAHULUAN}

STIPER Sriwigama Palembang merupakan salah satu perguruan tinggi ilmu pertanian dan kehutanan yang berada di Kota Palembang. Pada saat ini LAN (Local Area Network) telah dibangun dengan memanfaatkan beberapa switch dan router. LAN adalah sebuah jaringan yang dibatasi oleh area yang relatif kecil, umunya dibatasi oleh area lingkungan seperti sebuah kantor pada sebuah gedung atau tiap-tiap ruangan pada sebuah gedung [1]. Terdapat permasalahan pada pemberian IP address untuk setiap user yang masih dilakukan secara manual dengan konfigurasi IP address static kepada masing-masing user yang terdapat di lingkungan STIPER Sriwigama Palembang. IP address adalah sebuah indenfikasi unik dari sebuah komputer berupa logical address. IP address merupakan alamat yang mengandung informasi berharga yang dikodekan serta menyediakan kompleksitas routing. Saat ini banyak digunakan protokol IP versi 4. Sehingga ip addressnya pun sering disebut sebagai ip address versi 4 atau IPv4 atau ip address saja. Setiap komputer yang hendak bergabung dengan internet harus memiliki suatu alamat yang unik. Alamat ini berbeda dengan MAC ( media access control) address yang terdapat pada ethernet card [2]. Hal ini menjadi permasalahan akhir-akhir ini karena sering terjadi bentrokan IP address antar user yang juga disebabkan oleh pencatatan IP address yang kurang baik untuk masing-masing user. Tidak jarang juga terkadang user mengkonfigurasikan IP address-nya sendiri tanpa adanya konfirmasi ke pihak IT. Hal ini juga menyebabkan permasalahan dalam pengiriman data antar user yang berada di lingkungan STIPER Sriwigama Palembang.

Pada penelitian ini akan dilakukan perhitungan untuk pemetaan IP address pada STIPER Sriwigama Palembang dengan metode VLSM (Variable Length Subnet Mask). VLSM merupakan metode yang dilakukan untuk pengoptimalan pemetaan IP address terhadap user, dimana VLSM adalah pengembangan mekanisme subneting sehingga di dalam VLSM dilakukan peningatan dari kelemahan subneting klasik, yang mana dalam subneting klasik, subnet zeroes serta subnet ones tidak bisa digunakan. Selain itu, dalam subnet klasik, alokasi IP address tidak efisien [2]. Pada STIPER Srigama Palembang ini terdapat 3 router dan beberapa switch, sehingga perhitungan VLSM untuk pemetaan IP address dibagi menjadi 3 kelompok ruangan serta 3 router yang digunakan. Kelompok ruangan pertama terdiri dari Ketua, BAAK, BPM, Front Office dan Access Point Dosen, kelompok ruangan kedua terdiri dari Server, Wakil Ketua dan LPPM, sedangkan kelompok ruangan ketiga terdiri atas Bagian Pengajaran dan Access Point Mahasiswa. Adapun jumlah user pada kelompok ruangan pertama dibatasi 40 user, kelompok ruangan kedua berjumlah 8 user dan kelompok ruangan ketiga dibatasi 50 user.

\section{METODE PENELITIAN}

\subsection{Metode Action Research}

Dalam rangka penyelesaian penelitian ini maka digunakan metode penelitian Action Research yang merupakan salah satu bentuk rancangan penelitian, di dalam metode penelitian action research, peneliti mendeskripsikan, menginterpretasi dan menjelaskan suatu situasi sosial pada waktu yang bersamaan dengan melakukan perubahan atau intervensi dengan tujuan perbaikan atau partisipasi [3]. Berikut adalah gambar dan penjelasan terhadap tahapan metode penelitian action research yang digunakan pada penelitian ini, yaitu: 


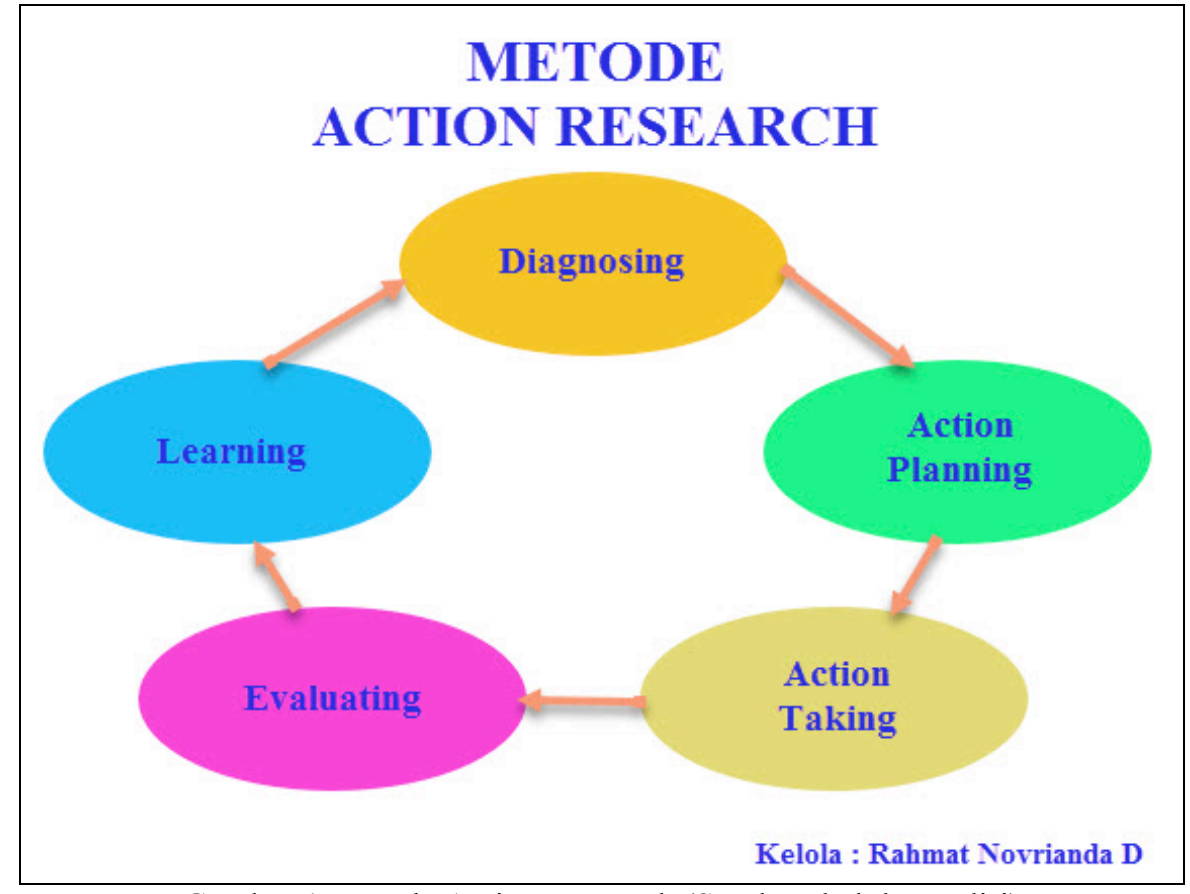

Gambar 1 Metode Action Research (Sumber: kelola sendiri)

\subsubsection{Melakukan diagnosa (diagnosing)}

Melakukan identifikasi permasalahan Pemetaan IP address untuk user yang terjadi pada STIPER Sriwigama Palembang dengan cara observasi dan juga wawancara terhadap pengelola IT disana, serta dosen dan staf.

\subsubsection{Membuat rencana tindakan (action planning)}

Membuat suatu perencanaan yang dapat dilakukan untuk memberi solusi ataupun menyelesaikan permasalahan LAN (Local Area Network) khususnya pemetaan IP address pada STIPER Sriwigama Palembang.

\subsubsection{Melakukan tindakan (action taking)}

Adapun tindakan yang dilakukan adalah melakukan pengamatan terhadap IP address yang saat ini digunakan dan memantau jumlah user sehingga IP address dapat dipetakan sesuai dengan jumlah user yang ada.

\subsubsection{Melakukan evaluasi (evaluating)}

Hasil pemetaan IP address dengan metode VLSM ini dilakukan evaluasi apakah sudah tepat ataukah belum dalam hal pemetaan IP address pada LAN STIPER Sriwigama Palembang. Jika pemberian IP address kepada user masih belum tepat, maka akan dilakukan perhitungan VLSM (Variable Length Subnet Mask) ulang.

\subsubsection{Pembelajaran (learning)}

Tahap ini merupakan tahap terakhir pada penelitian ini dimana dilaksanakan review, penyempurnaan serta penggabungan terhadap hasil dari tahap-tahap sebelumnya sehingga kemudian penelitian ini bisa diselesaikan dengan baik. 
Computatio: Journal of Computer Science and Information Systems, volume 2, no 2, Oktober 2018

\subsection{Langkah-langkah penelitian}

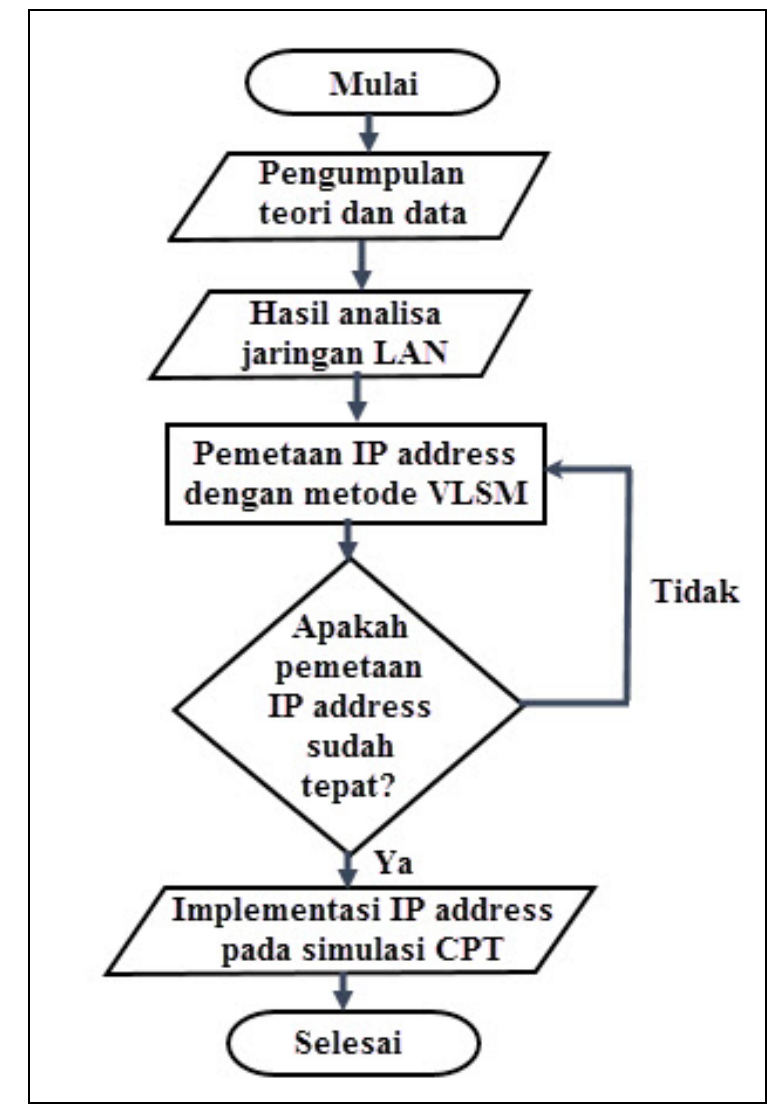

Gambar 2 Flowchart langkah-langkah penelitian (Sumber: kelola sendiri)

Gambar 1 di atas merupakan langkah-langkah penelitian yang dilakukan, diawali dari pengumpulan data yang berkaitan dengan kondisi LAN (Local Area Network) pada STIPER Sriwigama Palembang, baik topologi jaringan, perangkat jaringan yang digunakan hingga jumlah user yang ada serta IP address seluruh user. Selain itu, dengan bantuan mahasiswa dikumpulkan juga beberapa teori tentang pemetaan, IP address, subnet mask hingga VLSM (Variable Length Subnet Mask) dari berbagai referensi yang berkaitan. Kemudian, dilakukan analisa terhadap kondisi jaringan LAN pada STIPER Sriwigama Palembang, dimana didapatlah hasil jika terdapat permasalahan dalam hal pemetaan IP address jaringan LAN yang menyebabkan terjadi kesamaan IP address pada lebih dari 2 user sehingga mengganggu saat proses pengiriman data antar user tersebut. Selanjutnya dilakukan perhitungan VLSM untuk melakukan pemetaan IP address sehingga dapat memperbaiki permasalahan yang terjadi pada LAN STIPER Sriwigama Palembang. Apabila pemetaan IP address belum tepat, maka akan dilakukan perhitungan VLSM ulang, tetapi jika sudah tepat langsung diimplementasikan atau dicobakan pada simulasi Cisco Packet Tracer tentunya dengan melakukan konfigurasi routing pada simulasi tersebut sehingga seluruh user dapat terhubung dengan baik.

\section{HASIL DAN PEMBAHASAN}

VLSM merupakan teknik subneting terhadap jaringan yang sudah mengalami subneting dengan kata lain melakukan subneting pada sub network hasil dari subneting [4]. Hasil dari penerapan VLSM (variable length subnet mask) adalah pengguna prefix yang berbeda beda 
dalam suatu jaringan [5]. Sebelumnya, dibuat juga tabel bantuan untuk mempercepat perhitungan VLSM dan penentuan prefix-nya, sebagai berikut :

Tabel 1 Tabel bantuan perhitungan VLSM

\begin{tabular}{|c|c|c|c|}
\hline Host ke $2^{\mathrm{n}}$ & Jumlah Host & Subnet mask & Prefix \\
\hline $2^{0}$ & 1 & 255.255 .255 .255 & $/ 32$ \\
\hline $2^{1}$ & 2 & 255.255 .355 .254 & $/ 31$ \\
\hline $2^{2}$ & 4 & 255.255 .255 .252 & $/ 30$ \\
\hline $2^{3}$ & 8 & 255.255 .255 .248 & $/ 29$ \\
\hline $2^{4}$ & 16 & 255.255 .255 .240 & $/ 28$ \\
\hline $2^{5}$ & 32 & 255.255 .255 .224 & $/ 27$ \\
\hline $2^{6}$ & 64 & 255.255 .255 .192 & $/ 26$ \\
\hline
\end{tabular}

Adapun hasil dari penelitian ini merupakan perhitungan dengan metode VLSM untuk pemetaan IP address pada STIPER Sriwigama Palembang. Berikut ini adalah hasil perhitungan VLSM yang dimulai dari jumlah user terbanyak, yaitu kelompok ruangan ketiga dengan 50 user, kelompok ruangan pertama dengan 40 user dan kelompok ruangan kedua dengan 8 user. Dengan awal net ID 192.168.10.0, berikut ini hasil perhitungan VLSM :

\subsection{Kelompok ruangan ketiga}

Pada kelompok ruangan ketiga terdapat 50 user, sehingga untuk penentuan prefix maka termasuk ke dalam prefix /26 dengan subnet mask 255.255.255.192.

Tabel 2 Perhitungan VLSM pada kelompok ruangan ketiga

\begin{tabular}{|c|c|c|}
\hline Network & Ip Range & Broadcast \\
\hline .0 & $.1-.62$ & .63 \\
\hline .64 & $.65-.126$ & .127 \\
\hline .128 & $.129 .-.190$ & .191 \\
\hline .192 & $.193-.254$ & .255 \\
\hline
\end{tabular}

Dari tabel 2 di atas, dapat dipetakan untuk kelompok ruangan ketiga yang jumlah usernya adalah 50 user, IP address-nya 192.168.10.0/26 dengan network 192.168.10.0. Sehingga diperoleh range IP address dari 192.168.10.1 - 192.168.10.62 serta broadcast 192.168.10.63.

\subsection{Kelompok ruangan pertama}

Pada kelompok ruangan ketiga terdapat 40 user, sehingga untuk penentuan prefix maka termasuk ke dalam prefix /26 dengan subnet mask 255.255.255.192. 
Computatio: Journal of Computer Science and Information Systems, volume 2, no 2, Oktober 2018

Tabel 3 Perhitungan VLSM pada kelompok ruangan pertama

\begin{tabular}{|c|c|c|}
\hline Network & Ip Range & Broadcast \\
\hline .64 & $.65-.126$ & .127 \\
\hline .128 & $.129 .-.190$ & .191 \\
\hline .192 & $.193-.254$ & .255 \\
\hline
\end{tabular}

Dari tabel 3 di atas, dapat dipetakan untuk kelompok ruangan pertama yang jumlah usernya adalah 40 user, IP address-nya 192.168.10.64/26 dengan network 192.168.10.64. Sehingga diperoleh range IP address dari 192.168.10.65 - 192.168.10.126 serta broadcast 192.168.10.127.

\subsection{Kelompok ruangan kedua}

Pada kelompok ruangan kedua terdapat 8 user, sehingga untuk penentuan prefix maka termasuk ke dalam prefix /28 dengan subnet mask 255.255.255.240.

Tabel 4 Perhitungan VLSM pada kelompok ruangan kedua

\begin{tabular}{|c|c|c|}
\hline Network & Ip Range & Broadcast \\
\hline .128 & $.129-.142$ & .143 \\
\hline .144 & $.145-.158$ & .159 \\
\hline .160 & $.161-.194$ & .195 \\
\hline .196 & $.197-.210$ & .211 \\
\hline
\end{tabular}

Dari tabel 4 di atas, dapat dipetakan untuk kelompok ruangan kadua yang jumlah usernya adalah 8 user, IP address-nya 192.168.10.128/28 dengan network 192.168.10.128. Sehingga diperoleh range IP address dari 192.168.10.129 - 192.168.10.142 serta broadcast 192.168.10.143.

\subsection{Topologi jaringan LAN STIPER Sriwigama Palembang}

Hasil perhitungan pemetaan IP address dengan metode VLSM kemudian diimplementasikan pada topologi STIPER Sriwigama Palembang yang dibangun pada simulasi Cisco Packet Tracer (CPT) berikut ini: 


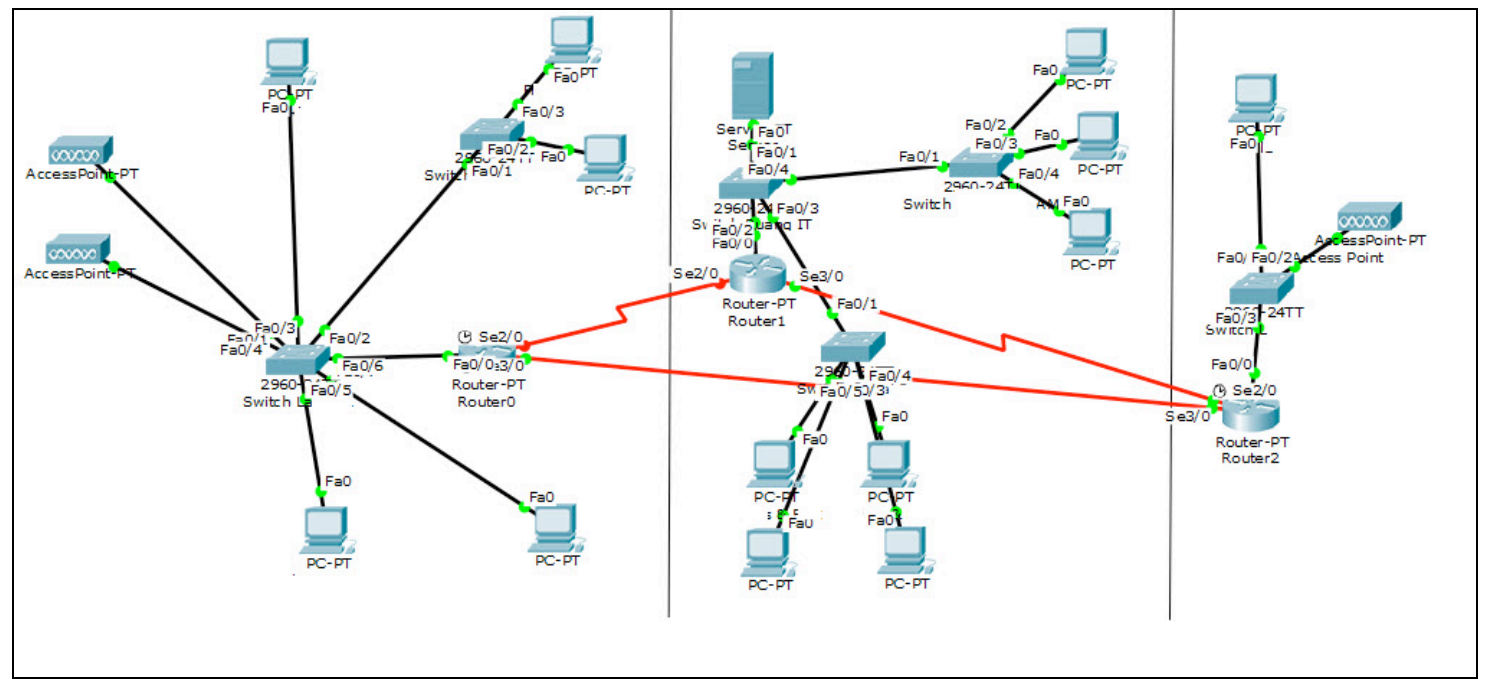

Gambar 3 Topologi STIPER Sriwigama Palembang pada simulasi CPT (Sumber : kelola sendiri)

\section{KESIMPULAN}

Pemetaan IP address dengan metode perhitungan VLSM (Variable Length Subnet Mask) memberikan solusi untuk pemberian IP address user secara tepat dan juga lebih terdata dengan rapi sehingga tidak lagi terdapat IP address yang sama antara dua atau lebih user yang menyebabkan gangguan pada proses pengiriman data. Selain itu, penggunaan IP address untuk user yang ada pada STIPER Sriwigama Palembang dapat lebih efektif dan efisien dengan metode VLSM ini.

\section{UCAPAN TERIMA KASIH}

Terima kasih diucapkan kepada ketua serta staf STIPER Sriwigama atas dukungan dan bantuannya, serta diucapkan juga terima kasih kepada mahasiswa yang telah membantu dalam pengumpulan data dan referensi berkaitan dengan penelitian yang dilakukan.

\section{DAFTAR PUSTAKA}

[1] Sofana, Iwan. 2008. Membangun Jaringan Komputer. Bandung: Informatika.

[2] Zaki, Ali. 2010. 60 Teknik Optimasi Jaringan Komputer. Jakarta: PT. Elex Media Komputindo.

[3] Pradnyadiputra, Oka; Sumadi, Wisnu; Christina, Dwi, (2009). Pemanfaatan Virtual Local Area Network (VLAN) dan Penghematan Host dengan Metode Variable Length Subnet Mask (VLSM). Bali.

[4] Davison, R., Martinsons, M. G., \& Kock, N. (2004). Principles of canonical action research. Information Systems Journal, 14(1), 65-86

[5] Sidik, Jafar. (2009). Teknik Konfigurasi Jaringan Virtual Local AreaNetwork (VLAN) Dan Penghematan Host Dengan Metode Variable Length Subnet Mask (VLSM). Bandung 